\title{
Dante, precursor de Borges
}

\author{
Humberto R. Núñez Faraco
}

Published online: 23 September 2014

(C) The Author(s) 2014. This article is published with open access at Springerlink.com

\begin{abstract}
This article examines Jorge Luis Borges's reading of Dante Alighieri and the imprint thereof on his own literary production. Despite the fact that Borges (1899-1986) assigned his reading of The Divine Comedy to a rather late period in his life, this study argues that he was acquainted with the work of the Italian poet (or at least part of it) at a much earlier date - as can be perceived in the poem 'Llamarada', published in 1920. It also shows that Borges's intention in dealing with Dante was not in itself parodical. On the contrary, it reveals his concern about the human condition and the ways in which literature can manifest man's being in the world.
\end{abstract}

Keywords Borges $\cdot$ Dante $\cdot$ Literary influence $\cdot$ Parody $\cdot$ Determinism $\cdot$ Free will

Tal como se manifiesta a través de sus ensayos y conferencias, la concepción borgesiana de la literatura supone una colaboración no antagónica que le permite al escritor recrear de manera positiva sus modelos artísticos. Más que ser asumida como una influencia dominante, la obra del predecesor se presenta como una forma "abierta" que ha de ser inventada (en cuanto adquiere un nuevo significado) por quien la reescribe: "En el vocabulario crítico, la palabra precursor es indispensable, pero habría que tratar de purificarla de toda connotación de polémica o rivalidad. El hecho es que cada escritor crea sus precursores". ${ }^{1}$ Este concepto de obra abierta

\footnotetext{
1 "Kafka y sus precursores" (1951), Borges (1989, II 89-90); el subrayado es de Borges. Según el crítico norteamericano Harold Bloom, cada poeta "fuerte" debe luchar por sobreponerse a sus predecesores. Dicho logro se consigue a través de lo que Bloom denomina "creative misprision", que consiste en la apropiación de las ideas forjadas por los grandes poetas del pasado. Como resultado de esta "lucha" (agon), se abre un nuevo campo semántico en donde el poeta fuerte hace oír su propia voz (Bloom 1997, 19-45).
}

H. R. Núñez Faraco $(\bowtie)$

Department of Spanish, Portuguese and Latin American Studies, University College London, Gower Street, London WC1E 6BT, UK

e-mail: uclshrn@ucl.ac.uk 
también implica su variabilidad interpretativa a través del tiempo, es decir, cada época lee la literatura de acuerdo a los parámetros culturales que le son propios. ${ }^{2}$ Por eso afirma Borges: "El poema Fears and Scruples de Browning profetiza la obra de Kafka, pero nuestra lectura de Kafka afina y desvía sensiblemente nuestra lectura del poema. Browning no lo leía como ahora nosotros lo leemos" (1989, II 89).

Como es sabido, Borges desarrolla el concepto de "infidelidad creadora" en el ensayo "Los traductores de las 1001 Noches" (1935), donde elogia la versión libre e imaginativa de Jean-Charles Mardrus (1868-1949). Al discutir la traducción del mencionado médico francés, Borges hace a un lado la cuestión de la exactitud de la obra con respecto al original, y exalta en cambio los logros expresivos del texto derivado: "Su infidelidad, su infidelidad creadora y feliz, es lo que nos debe importar" (1989, I 410). ${ }^{3}$

Borges indica de este modo su fe total en la autonomía del escritor/traductor frente a la tradición. Si el autor es libre de elegir a sus predecesores, y si dicha libertad artística se ha verificado en la historia como un acto que enriquece el conjunto de la tradición literaria, la idea de perpetuar una literatura "nacional" (tal como se lo planteaba el nacionalismo cultural argentino a partir de la década de 1910) se revela como una determinación limitante y empobrecedora. De ahí que Borges afirme en otro lugar: "Creo que nuestra tradición es toda la cultura occidental, y creo también que tenemos derecho a esta tradición". 4

Además de resaltar el aspecto subjetivo que otorga la voluntad creadora frente a la preponderancia de un supuesto canon nacional, Borges rechaza los postulados estéticos del nacionalismo en la medida en que éste intenta fomentar la politización de las masas a través del arte y la literatura. Afirma, por el contrario, que la obra literaria subsiste no en virtud de las intenciones políticas del autor, sino por la profundidad de pensamiento y emoción que el autor logra plasmar en ella, junto con su capacidad para producir un goce estético de carácter universal. ${ }^{5}$ En suma, Borges no busca la esencia de lo argentino en sus manifestaciones externas sino en la interioridad del individuo. De ahí que, en su interpretación de los sonetos del poemario La urna (1911) de Enrique Banchs, Borges encuentre en la expresión individual del sentimiento poético un elemento común a todos los argentinos, el cual

\footnotetext{
2 "Clásico es aquel libro que una nación o un grupo de naciones o el largo tiempo han decidido leer como si en sus páginas todo fuera deliberado, fatal, profundo como el cosmos y capaz de interpretaciones sin término", Borges (1989, II 150-151); énfasis añadido.

3 Véase Waisman $(2005,139-146)$.

4 "El escritor argentino y la tradición", conferencia dictada en 1951 y divulgada especialmente a raíz de su publicación en la revista Sur, 232 (1955) 1-8 (cfr. Borges 1989, I 272). Para una contextualización, véase King (1986, 145-152); Sarlo (1995, 66-69, 105-108); Sitman (2003, 165-173); Siskind (2007, 75-92); Contreras (2008, 92-94); Fiorucci (2011, 125-142); Balderston (2013, 2-12).

5 Véase "El escritor argentino y la tradición”, Borges (1989, I 273-274). El germen de la idea se halla expresado en algunos de sus ensayos juveniles; véase Borges (1926, 153) y Borges (1928, 182-183).
} 
radica precisamente en "la dificultad que tenemos para las confidencias, para la intimidad" (1989, I 270). ${ }^{6}$

En este sentido, Borges halló en el Ulises dantesco una poderosa representación de la pesquisa que el poeta hace tanto de la experiencia vital como de su propia actividad literaria. Más específicamente, en el ensayo "El último viaje de Ulises", observa que el reto de Dante en esa etapa de la obra consistía en dar por terminada la Comedia, en espera de su difusión pública y la muy probable condena política y religiosa de que sería objeto. Agobiado por la incertidumbre, Dante habría comparado su empresa temeraria (la concepción del poema) con la trágica expedición de Ulises. En palabras del escritor: "La acción de Ulises es indudablemente el viaje de Ulises, porque Ulises no es otra cosa que el sujeto de quien se predica esa acción, pero la acción o empresa de Dante no es el viaje de Dante, sino la ejecución de su libro." 7 Borges debe haber sido muy sensible a esta inquietud, puesto que finaliza uno de los escasos poemas que escribió durante este período ("Mateo, $\mathrm{XXV}, 30$ ") con un severo juicio acerca de sus propios logros poéticos:

En vano te hemos prodigado el océano,

En vano el sol, que vieron los maravillados ojos de Whitman:

Has gastado los años y te han gastado,

Y todavía no has escrito el poema. (Borges 1989, II 252)

Como ya lo indica la mención al renombrado poeta norteamericano, Dante no es más que una entre muchas otras influencias literarias presentes en la obra de Borges. Esto se debe, como puede inferirse de lo ya dicho, a la enorme variedad de sus lecturas, que se extendían más allá de sus fronteras nacionales y lingüísticas a fin de abarcar el conjunto de la literatura universal. Entre sus actitudes intelectuales características sobresale el reconocimiento de la palabra escrita en diversas épocas y lugares, actitud que le permitió ubicar su vocación poética en un amplio marco de referencias culturales. Esta visión de la literatura—que podría resultar paradójica si se examina a la luz de los principios del nacionalismo cultural que profesó en la década de 1920 - es un reflejo de su afinidad con la cultura europea, afinidad que se explica no sólo por su formación escolar en Suiza, sino también por sus antecedentes familiares y su temprana iniciación en la literatura inglesa. ${ }^{8}$ No ha de sorprender, entonces, que el criollismo de Borges durante los años veinte se manifieste como una voluntad creadora que reclama para sí toda la cultura occidental: "Borges rechaza un criollismo basado en el color local y la nostalgia, y reivindica una tendencia universalista" (Gil Guerrero 2008, 71).

\footnotetext{
${ }^{6}$ Por la misma razón, en el ensayo "La poesía gauchesca" Borges insiste en los aspectos intrínsecos del Martín Fierro ("la verdad del sentimiento del héroe", "la narración del paisano, el hombre que se muestra al contar”) frente al presunto carácter épico del poema, según la tesis lugoniana (Borges 1989, I 196-197; énfasis añadido). Véase Sarlo (1995, 85-93).

7 Borges (1989, III 355). Para un detallado análisis véase Iglesias (2012, 282-301).

8 "The writers whose literary influence I consciously assimilated were Stevenson, Chesterton, Kipling and Shaw, authors I read when I was still a young boy growing up in Buenos Aires and spending a considerable amount of my time in my father's library which contained a remarkable collection of English books" (Heaney y Kearney 1983, 73). Con referencia a Whitman, véase Díaz (2012, 116-160).
} 
Ahora bien, en Nueve ensayos dantescos Borges da cuenta de su dantismo al citar a no menos de treinta autores-desde los primeros comentaristas de la Comedia hasta escritores y críticos modernos-poniendo de presente su interés por el poeta italiano. Años más tarde, al preguntársele: "Does he mean as much to you as your favourite English [...] and American poets?", Borges respondió de modo inequívoco: "Were I to save a whole book [...] I would save the Divine Comedy [...] I think of Dante as being the writer, as being the poet" (Cortínez 1986, 86-87; énfasis en el original).

Borges plasma sus pensamientos más elaborados en torno a la obra de Dante en 'La Divina Comedia' (Borges 1989, III 207-20)-primera de una serie de conferencias sobre temas literarios impartidas en 1977-y los ya mencionados Nueve ensayos dantescos (1982), que recogen parte del material que el autor había publicado más de treinta años antes, junto con algunos ensayos posteriores (Borges 1949). Tomados en su conjunto, no obstante, dichos escritos dejan ver que el análisis de Borges estaba lejos de abordar las diversas complejidades de la Comedia. Sin embargo, al estudiar su obra crítica es necesario tener siempre en cuenta el tipo de lector al que Borges se dirigía. Los ensayos sobre Dante fueron concebidos para un público general y en tal sentido Borges cumple una labor de difusión pedagógica. Con todo, es improbable que hubiera llegado a desarrollar un interés filológico y exegético de tal naturaleza como para emprender por iniciativa propia un estudio extensivo del poema. Aunque haya sido un ávido lector, Borges no se ubica en la categoría de los italianistas y medievalistas, por lo que su aproximación a Dante es siempre imaginativa, no académica.

También hay referencias ocasionales a Dante en las entrevistas que concedió Borges tras alcanzar reconocimiento internacional a finales de la década de 1950. Sin embargo, debido al carácter espontáneo de las mismas, no puede decirse que éstas constituyan una reflexión sistemática a partir de la cual se pueda elaborar una teoría poética. Nunca menciona Borges, por ejemplo, el tratado De vulgari eloquentia-donde Dante examina la lengua vulgar itálica y su adecuación a la expresión poética-ni hace referencia alguna a otros pasajes que suelen ser objeto de estudio entre los especialistas, tales como el Capítulo XXV de la Vita Nuova y los Cantos XXIV-XXVI del Purgatorio. Lo que sí se descubre en su crítica literaria es un interés común acerca de ciertos aspectos del lenguaje en relación con el proceso creativo. Sobre todo, el gran aprecio que profesaba Borges por el poeta italiano parte de su admiración por la maestría en el uso del lenguaje y su destreza para crear una emoción estética carente de artificios retóricos. ${ }^{9}$

A pesar de que sólo en un período relativamente tardío de su vida hizo Borges una lectura minuciosa de la Comedia (Borges 1961), sus primeras alusiones críticas a Dante se encuentran en los ensayos que publicó a su regreso a la Argentina tras su

\footnotetext{
9 Al comparar la imagen "Dolce color d'oriental zaffiro" (Purgatorio I, 13) con su equivalente en las Soledades de Góngora ("en campo de zafiros pasce estrellas"), Borges afirma: "El verso del Purgatorio es delicado; el de las Soledades es deliberadamente ruidoso" (Borges 1989, III 364). Cfr. Borges (1982, 81-82): "La retorica dovrebbe essere un ponte, una strada, ma in genere è una muraglia, un ostacolo [...] Direi che Dante ci permette di conoscerlo, ci permette un rapporto di intimità, e perfino in un modo più personale di quanto sarebbe potuto accadere ai suoi contemporanei." Para una visión de conjunto, véase Paoli (1977) y (1984); Núñez Faraco (2012, 645-54).
} 
segundo viaje a Europa en 1924. Aunque en ellos no se percibe un conocimiento profundo del poeta italiano, hay no obstante una instancia en la poesía juvenil de Borges que indica su familiaridad con el Canto $\mathrm{V}$ del Infierno. Me refiero, específicamente, al famoso episodio de Francesca da Rimini, del cual podemos encontrar un eco en el poema "Llamarada", publicado en 1920. Este hecho, por sí solo, no puede interpretarse como si el autor ya estuviera plenamente familiarizado con la Comedia en aquel entonces. Sin embargo, dada la inmensa popularidad de este episodio (especialmente entre los poetas románticos que Borges había leído con avidez en su juventud), es lícito asumir que tuviera algún conocimiento de él. Más aún, el hecho de que en sus ensayos posteriores sobre Dante se vislumbre un interés romántico por las figuras de Paolo y Francesca, al igual que Beatrice, Ulises y Ugolino, indica que su lectura de Dante pudo estar mediada-al menos en sus inicios-por escritores y comentaristas del siglo XIX, quienes habrían dejado una huella profunda en el poeta argentino. De igual modo, los románticos exaltaron la importancia biográfica del poema en cuanto a la significación afectiva de Beatrice, cuya expresión más apasionada se encuentra en Purgatorio XXX (Arnold 1962, 3-11), canto que, como se verá más adelante, ocupa un lugar central en la lectura que hace Borges del Dante. Por lo tanto, me atrevo a conjeturar que para el año de 1920 Borges tenía conocimiento de los episodios más renombrados de la Comedia-especialmente aquellos que los escritores románticos percibían como los más representativos de la individualidad heroica-, lo cual no contradice en modo alguno sus declaraciones con respecto a una lectura sistemática de la obra en fecha posterior.

"Llamarada" fue publicado por primera vez en Sevilla bajo el título "La llama" (Grecia, febrero de 1920). Es, por lo tanto, contemporáneo al período ultraísta en el cual se inició Borges durante su primera visita a España entre 1919 y 1920. De modo similar a otras composiciones de la época, el poema se inicia con una descripción pictórica del paisaje en el que se proyecta el estado anímico del poeta:

Bajo la dolorida sombra del cielo - ante los austeros mástiles que se alzan sobre las aguas sin ruido - y las luces pobres del puerto que en amplia inmóvil procesión, anilladas de rojo en la penumbra lo ciñen, - una llamarada ondula en el aire pardo y pesado a ras de la tierra - en el derrumbamiento de las cosas visibles, - en la angustiosa espera de la tormenta cercana. ${ }^{10}$

A continuación el poeta vuelca su atención a la llama que arde en la orilla del mar, a la cual confiere una voz apasionada:

Yo, latente bajo todas las máscaras, - nunca apagada y eternamente acechando [...] encarno la grande fatiga, la sed de no ser de todo cuanto en esta tierra poluta vibra, y sufriendo vive.

A medida que se revela el sentido del poema, descubrimos que en él se manifiesta el drama de la pasión erótica que aboca al ser humano a sufrir el ciego impulso del deseo carnal:

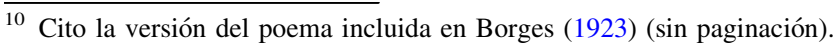


Medito el significado de tu roja palabra - y veo que en verdad eres símbolo de nosotros que inevitablemente sufrimos - uncidos al gris yugo del día - o al enjoyado yugo de la noche - y ansiamos como tú la alta serenidad y el desdén claro de la felina noche...

Espoleados - deseando deslumbrarnos y perdernos en las culminaciones carnales - en la crucifixión de cuerpos tremantes [...] - Y la llama se hunde en el gran crepúsculo enfermo - que en girones [sic] desgarran los grises vientos.

El estilo de que hace gala Borges en estos versos contrasta con el sentimentalismo de sus primeros poemas de amor. Es particularmente impactante la metáfora de la crucifixión, que da a entender que la unión lujuriosa de los cuerpos ("deseando deslumbrarnos y perdernos en las culminaciones carnales-en la crucifixión de cuerpos tremantes") constituye un acto de inmolación que trae consigo la ruina espiritual, tal como está implícito en la referencia al Canto V del Infierno: “i peccator carnali, I che la ragion sommettono al talento"; "Amor condusse noi ad una morte" (Inferno V, 38-39 y 106). Esta metáfora se refuerza en la tercera estrofa del poema con la frase "en esta tierra poluta". Nótese también la anticipación de la atmósfera religiosa contenida en la primera estrofa, donde el poeta compara las luces del puerto con una inmóvil procesión, imagen que evoca las celebraciones de la Semana Santa.

Por otra parte, el uso del adjetivo "tremantes" llama la atención no sólo por ser hapax legomenon en la obra de Borges sino también porque evoca uno de los episodios más famosos en toda la historia de la literatura amorosa: la trágica leyenda de Paolo y Francesca narrada por Dante en el mencionado canto. Al relatar el momento crucial de su enamoramiento, Francesca dice:

Quando leggemmo il disiato riso

esser basciato da cotanto amante, questi, che mai da me non sia diviso,

la bocca mi basciò tutto tremante.

$$
\text { (Inferno } \mathrm{V}, 133-36 \text { ) }
$$

Esto no es todo, sin embargo. La descripción "los grises vientos" y el paisaje tormentoso en que se desenvuelve el poema son igualmente significativos, porque son imágenes como éstas las que confieren su carácter peculiar al escenario alegórico del segundo círculo del Infierno, en donde Paolo y Francesca han sido confinados por su transgresión amorosa: "Io venni in luogo d'ogne luce muto, I che mugghia come fa mar per tempesta, I se da contrari venti è combattuto" (Inferno V, 28-30). Aún más, la pesadez del aire en el poema de Borges ("en el aire pardo y pesado") es reminiscente de "l'aura nera" y "l'aere perso" de Dante (versos 51 y 89). El participio "espoleados", igualmente, se corresponde con el verbo italiano "menare", presente en los versos 32, 43 y 78 del mismo canto. En las primeras dos menciones, Dante utiliza el término para describir la tormenta infernal que arrastra a su paso las almas pecaminosas:

La bufera infernal, che mai non resta, mena li spirti con la sua rapina $[\ldots]$ 
Così quel fiato li spiriti mali

di qua, di là, di giù, di sù li mena;

nulla speranza li conforta mai, non che di posa, ma di minor pena.

$$
\text { (Inferno V, 31-32, 42-45) }
$$

En tanto que el verso 78 describe el poder del amor incestuoso que empuja las almas desventuradas de Paolo y Francesca ("per quello amor che i mena"), la furia del último verso del poema de Borges ("que en girones desgarran los grises vientos") hace eco del término "rapina" (utilizado por Dante en el verso 32), así como la ruinosa condición de las almas enceguecidas por la pasión del deseo: "Quando giungon davanti a la ruina, I quivi le strida, il compianto, il lamento" (versos 34-35). Si Dante concibe el amor concupiscente como un impulso destructivo que lo arrasa todo, el poema de Borges percibe lo carnal como un aspecto enfermizo de la existencia humana en el que se pierden la autodeterminación y libertad propias.

Por otra parte, la sexualidad presente en la metáfora de la crucifixión contrasta fuertemente con la muerte de Cristo (en tanto acto de amor por la salvación del hombre), al igual que con el amor de Dante por Beatrice, que prometía superar los obstáculos de la pasión mundana a fin de alcanzar un orden espiritual más elevado. Frente al trágico ejemplo del amor cortés encarnado en Paolo y Francesca, Dante contrapone más adelante su propia versión del amor benigno cuando éste se encamina por la via recta de la razón. La lección moral decisiva se formula en el Canto XXX del Purgatorio:

Donna m'apparve, sotto verde manto vestita di color di fiamma viva.

E lo spirito mio, che già cotanto

tempo era stato ch'a la sua presenza

non era di stupor, tremando, affranto,

sanza de li occhi aver più conoscenza,

per occulta virtù che da lei mosse, d'antico amor sentì la gran potenza.

Tosto che ne la vista mi percosse

L'alta virtù che già m'avea trafitto prima ch'io fuor di püerizia fosse,

volsimi a la sinistra col respitto

col quale il fantolin corre a la mamma

quando ha paura o quando elli è afflitto,

per dicere a Virgilio: "Men che dramma

di sangue m'è rimaso che non tremi:

conosco i segni de l'antica fiamma."

(Purgatorio XXX, 32-48; énfasis añadido)

La metáfora del fuego como expresión del amor apasionado es-ya lo sabemosde vieja data. El propio Dante la toma prestada de Virgilio (Eneida IV, 23), otro autor admirado por Borges, quien había leído a los poetas latinos durante sus años de estudio en Suiza. Ahora bien, la importancia de los citados pasajes para una 
lectura de "Llamarada" está dada por el énfasis que Borges le daría más tarde al encuentro de Dante y Beatrice en el Canto XXX del Purgatorio, momento que percibe como el punto medular de la Comedia: "Yo tengo para mí que [Dante] edificó la triple arquitectura de su poema para intercalar ese encuentro" (Borges 1989, III 371). En el mismo ensayo, Borges parafrasea los versos 32-48 del Purgatorio citados anteriormente:

El carro se detiene y una mujer velada aparece; su traje es del color de una llama viva. No por la vista, sino por el estupor de su espíritu y por el temor de su sangre, Dante comprende que es Beatriz. En el umbral de la gloria siente el amor que tantas veces lo había traspasado en Florencia. (Borges 1989, III 369)

Dada la centralidad de este episodio en la interpretación que hace Borges de la obra, es pertinente examinar de qué manera los citados versos se corresponden con la lectura que hacemos de "Llamarada". Limitando nuestro análisis a la dimensión afectiva, la importancia de la apropiación que hace Dante del verso virgiliano ("conosco i segni de l'antica fiamma") radica en el correctivo moral que éste le aplica al predecesor (Mazzotta 1979, 186). En los versos latinos es Dido quien descubre la pasión naciente por Eneas, cuya atracción le impide mantener votos de castidad (Eneida IV, 28-29, 552). El encuentro resulta fatal para ella: incapaz de aceptar el abandono de Eneas, despierta el odio de su nación contra los dánaos para luego quitarse la vida (Eneida IV, 584-665). Dante ubica a Dido en el segundo círculo del Infierno junto con Francesca y todos aquellos cuya pasión desbordada ha manchado la tierra con sangre ("noi che tignemmo il mondo di sanguigno", Inferno $\mathrm{V}, 90$ ). A lo que quiero llegar es a lo siguiente: Beatrice representa un acogimiento del amor basado en la edificación moral de la persona, en tanto que el ardor sin límites de Dido por Eneas se torna autodestructivo, lo cual ilustra cómo un impulso esencialmente benéfico puede envenenar a quien lo experimenta si no es debidamente controlado (nótese, de paso, el reproche moral de Beatrice a Dante en Purgatorio XXX, 55-145). Desviado de sus fines naturales, Eros se torna un demonio ávido de sangre y venganza. Esta clase de amor es, dentro de la economía de la Comedia, una forma de esclavitud que impide el crecimiento espiritual del ser humano.

Esto nos trae de vuelta a las imágenes del yugo y la crucifixión en el poema de Borges. Evidentemente, la tensión de los términos le otorga fuerza creativa al poema al juntar lo sagrado y lo profano. Lo que atrae mi atención de este poema es, sin embargo, su tensa ambigüedad. Se trata, ciertamente, de una reflexión acerca de la existencia humana, sujeta como está a impulsos ciegos y destructivos; al mismo tiempo, el poema es una imagen poderosa de las fuerzas ocultas que subyacen al quehacer humano, y también el clamor del poeta por alcanzar la plenitud amorosa. El tono de desesperanza y ofuscamiento de los versos finales ("Y la llama se hunde en el gran crepúsculo enfermo-que en girones desgarran los grises vientos") es acorde con las palabras finales del peregrino en el mencionado canto del Infierno: "E caddi come corpo morto cade" (Inferno V, 142).

Paso a continuación a dar una visión más amplia de los aspectos que resalta Borges en sus ensayos sobre Dante. En ellos se revela, en primera instancia, la presencia de un juicio estético que hace hincapié en la respuesta emocional del 
lector frente a la substancia poética del texto. Así como Borges trae a primer plano el valor poético de la Comedia, también cuestiona su capacidad para apreciar la dimensión teológica del poema: "The fact that I am not a Christian makes my judgment of Dante to be simply an aesthetic one" (Cortínez 1986, 86). Junto con la apreciación estética de la obra que nos ocupa, Borges destaca los siguientes temas: (1) la necesidad de que la poesía suscite de modo auténtico el sentimiento y la emoción; (2) la conexión entre el arte y la realidad; (3) la cuestión del libre albedrío; y (4) la naturaleza y significado del amor de Dante por Beatrice. Puede decirse que los aspectos que Borges destaca en su Lectura Dantis hacen parte del repertorio poético y filosófico que anima su propia obra literaria.

Entre las alusiones directas a la Comedia en la poesía de Borges se destacan los poemas “Paradiso, XXXI, 108”, “Inferno, I, 32” (El hacedor, 1960), e "Inferno, V, 129" (La cifra, 1981), que invierte la condena dantesca del amor ilícito: "Son Paolo y Francesca I y también la reina y su amante I y todos los amantes que han sido I desde aquel Adán y su Eva I en el pasto del Paraíso" (Borges 1989, III 323, versos 15-19). De otra parte, en "Poema conjetural" Borges crea un paralelo con el Canto V del Purgatorio (versos 94-102), e inserta una traducción literal del verso 99: "fuggendo a piede e sanguinando il piano" ("huyendo a pie y ensangrentando el llano", Borges 1989, II 245, verso 14) con el que describe la trágica muerte de uno de sus antepasados, Francisco de Laprida; táctica que emplea en el poema "El Ángel" (La Cifra, 1981), donde intercala el último verso de la Comedia ("l'amor che move il sole e l'altre stelle", Par. XXXIII, 145), incorporando de este modo el aspecto ético-religioso de mayor relevancia en la obra del Dante:

Que el hombre no sea indigno del Ángel

cuya espada lo guarda

desde que lo engendró aquel Amor

que mueve el sol y las estrellas

hasta el Último Día en que retumbe

el trueno en la trompeta. ${ }^{11}$

Con referencia al destino trágico del hombre, son particularmente impactantes los versos de "Poema conjetural". Allí, Borges sugiere que todo evento histórico ha sido de algún modo prefigurado por otro que lo antecede:

Como aquel capitán del Purgatorio que, huyendo a pie y ensangrentando el llano, fue cegado y tumbado por la muerte donde un oscuro río pierde el nombre, así habré de caer. ${ }^{12}$

\footnotetext{
11 Borges (1989, III 320); versos 1-6. Para un estudio de las apariciones textuales de Dante en la obra de Borges, véase Rodríguez Risquete (2005).

12 Borges (1989, II 245); versos 13-17. El soldado al cual se alude es el guibelino Buonconte da Montefeltro, muerto en batalla en el año 1289. A través de la comparación Laprida-Buonconte, Borges crea una estructura temporal que se sustenta en el mito del eterno retorno. Para un análisis del poema, véase Carilla (1963, 32-45); Paoli (1997, 109-118); Alonso (2002, 93-113); Durante (2008, 299-314).
} 
El "Poema conjetural" fue publicado en el diario La Nación el 4 de julio de 1943, exactamente un mes después del golpe militar efectuado contra los regímenes militares de corte conservador que habían dominado el escenario político argentino de la década anterior. La decisión de publicar el poema justo en ese momento tenía, por lo tanto, una motivación política. ${ }^{13}$ En el poema, Borges dramatiza la muerte de su ilustre ancestro, Francisco de Laprida, quien había presidido las deliberaciones del Congreso de Tucumán que declaró la independencia de las Provincias Unidas del Rio de la Plata en 1816. Laprida-que era liberal y partidario de las políticas unitarias-murió luchando contra las fuerzas federales comandadas por los hermanos Aldao en las guerras civiles que siguieron a la independencia de la Argentina:

\section{[...] Al fin me encuentro}

con mi destino sudamericano.

A esta ruinosa tarde me llevaba

el laberinto múltiple de pasos

que mis días tejieron desde un día

de la niñez. Al fin he descubierto

la recóndita clave de mis años,

la suerte de Francisco de Laprida,

la letra que faltaba, la perfecta

forma que supo Dios desde el principio.

En el espejo de esta noche alcanzo

mi insospechado rostro eterno. El círculo

se va a cerrar. Yo aguardo que así sea. (versos 28-38)

Borges acude en estos versos a la noción del destino como desenvolvimiento de la existencia humana que halla su sentido final en el encuentro con la muerte. Sin embargo, la imagen del círculo en los versos 37-38 indica la presencia de un elemento pagano (el concepto del tiempo circular) que contrasta con la idea del progreso lineal típico del pensamiento cristiano. ${ }^{14}$ Lejos de afirmar los principios escatológicos sobre los que se erige la Comedia, la muerte de Laprida implica la existencia de fuerzas negativas (peculiares a su circunstancia) que determinaron el trágico fin del personaje: "Al fin me encuentro I con mi destino sudamericano" (versos 29-30). Por lo tanto, la imagen del círculo sugiere la ausencia de un verdadero progreso en el orden espiritual tal como se da en Dante. Si el progreso histórico conlleva un principio ideal que lo empuja hacia adelante, el movimiento circular parece condenar al sujeto a una repetición fútil, si no a su total obliteración. Aunque perfecto en su forma, el círculo que se cierra con la muerte de Laprida no implica el logro de una plenitud existencial ni tampoco la posibilidad de cambio, ya

\footnotetext{
${ }^{13}$ En conversación con Osvaldo Ferrari, Borges explica el sentido del poema: "Cuando yo publiqué ese poema, el poema era no sólo histórico del pasado sino histórico de lo contemporáneo; porque cierto dictador acababa de asumir el poder, y todos no encontramos con nuestro destino sudamericano. [...] De modo que en aquel momento quienes leyeron eso lo sintieron como actual" (Borges and Ferrari 1987, 25).

14 "San Agustín dice con una hermosa metáfora que la cruz de Cristo nos salva del laberinto circular de los estoicos" (Borges 1979, 165-166).
} 
sea individual o colectivo (es decir, en cuanto destino "sudamericano"); es tan sólo la tácita aceptación de las fuerzas externas que determinaron de manera ineludible su existencia, obligándolo, quizá, a deambular ciegamente por el laberinto de la eternidad. $^{15}$

Por otra parte, la apropiación de la Comedia en la obra de ficción de Borges tiende a efectuarse de manera más oblicua. Así, en el cuento "La intrusa" (El informe de Brodie, 1970)—que trata de los celos de dos hermanos enamorados de la misma mujer-, Borges utiliza la técnica narrativa empleada por Dante en el episodio de Francesca da Rimini (Inferno V, 73-142), haciendo que sólo uno de los tres personajes del cuento se exprese en estilo directo. De igual modo, en los relatos "El Aleph", "El Zahir" y "La escritura del dios" (de la colección El Aleph, 1949), Borges intercala alusiones a Dante con otros elementos literarios, místicos y filosóficos tomados de autores medievales y renacentistas. Es así como la figura histórica de Pier Damiani (mencionado por Dante en Paradiso XXI, 121-123) sirve de pretexto para un relato fantástico en que Borges especula sobre las nociones de tiempo e identidad ("La otra muerte", Borges 1989, I 571-575); en tanto que el cuento "La espera" retrata el delirio psicótico de un hombre que-al igual que las almas pecaminosas del infierno dantesco_-es incapaz de escapar a su propia ceguera moral: "[Villari] no juzgó inverosímiles o excesivas las penas infernales y no pensó que Dante lo hubiera condenado al último círculo, donde los dientes de Ugolino roen sin fin la nuca de Ruggieri" (Borges 1989, I 610).

Veamos con más detenimiento este último ejemplo. A pesar de la lectura de los cantos correspondientes del Infierno — donde se purga el pecado de la traición-, el personaje no puede o no quiere reconocer su propia condición en los antecedentes expuestos en el poema. Afirma Borges en su discusión acerca de este famoso pasaje que: "Negar o afirmar el monstruoso delito de Ugolino [el canibalismo] es menos tremendo que vislumbrarlo" (Borges 1989, III 353). Esto da muestras de una técnica narrativa en la que se plantea un interrogante ético que va más allá de lo expuesto al lector. En efecto, para Borges "un libro es más que una estructura verbal. [...] El libro no es un ente incomunicado: es una relación, es un eje de innumerables relaciones" (Borges 1989, II 125). En este eje de relaciones, la palabra escrita adquiere una significación moral cargada con posibilidades reales. Como dice uno de sus personajes: "Más ardua que la empresa de Napoleón fue la de Raskolnikov" ("Deutsches Requiem", Borges 1989, I 578). En un aparte de Nueve ensayos dantescos, Borges opina acerca de aquel inolvidable personaje dostoievskiano: "Raskolnikov, para quien ha leído su historia, es un ser verdadero" (Borges 1989, III 358).

En este último ensayo, Borges aborda los conceptos de causalidad y libre albedrío. Una vez más, la discusión se centra en el personaje de Francesca da Rimini. La pregunta que agobia a Borges es la siguiente: Dante escucha con simpatía el relato de Francesca y, sin embargo, la condena al infierno: “¿Cómo atenuar esa discordia, cómo justificarla?” (Borges 1989, III 357). Luego de explorar algunas de las respuestas que otros críticos han dado al problema, Borges expone su

\footnotetext{
15 "Mi teoría personal de la eternidad" — escribe Borges en un ensayo juvenil— "es una pobre eternidad ya sin Dios, y aun sin otro poseedor y sin arquetipos" (Borges 1989, I 365).
} 
propia visión del asunto: “[Dante] sintió (no comprendió) que los actos del hombre son necesarios y que asimismo es necesaria la eternidad, de bienaventuranza o de perdición, que éstos le acarrean" (Borges 1989, III 359). Esta conclusión es antecedida por un breve análisis de la conducta humana en el que arguye que dicho actuar depende de una cadena causal infinita. La causalidad, vista como un nexo despiadado y absoluto, rige el comportamiento de los hombres y hace que sus decisiones sean inevitables: "Quien ha leído la novela de Dostoievsky ha sido, en cierto modo, Raskolnikov y sabe que su 'crimen' no es libre, pues una red inevitable de circunstancias lo prefijó y lo impuso."16

Ahora bien, la interpretación psicológica que presenta Borges hace caso omiso (por medio de una frase parentética que elimina toda posibilidad de discusión) de la conexión entre la pasión amorosa y el libre albedrío desarrollada por Dante en los cantos centrales del Purgatorio. Para Dante, el mérito de la voluntad que actúa en conformidad con la razón ("intelletto") reside en su absoluto control del apetito sensual:

Onde, poniam che di neccessitate

surga ogne amor che dentro a voi s'accende,

di ritenerlo è in voi la podestate.

(Purgatorio XVIII, 70-72)

Borges modifica de este modo el significado profundo del mencionado paso, ya que le atribuye a Dante una concepción determinista del actuar humano contraria a la doctrina del libre albedrío mantenida en la Comedia. ${ }^{17}$

Al igual que lo hiciera Dante, Borges expresa a través de su obra una preocupación acerca de la condición humana. Sin embargo, siguiendo una tendencia arraigada en el mundo contemporáneo, su visión tiende a estar cargada de pesimismo. Lo que encontramos en sus escritos es con frecuencia una conciencia agobiada por la duda y el descreimiento, antes que una convicción de la plena capacidad del Ser basada en sus posibilidades trascendentes. Por ello, el límite del conocimiento se revela como un estado de ilusión o engaño imposible de superar. En muchos de sus relatos y poemas con temas dantescos esto se traduce en un escepticismo radical que permea todos los aspectos de la existencia: así, el hombre es el ejecutor de una voluntad ajena; la historia, una tragicomedia que hemos de representar una y otra vez; el amor, una fuerza irracional que nos encadena o envilece. Los orígenes de su concepción son muy variados, e incluyen una variedad de fuentes clásicas, cristianas y neoplatónicas-Marco Aurelio, Plotino y San Agustín, entre otros-que Borges leyó con entusiasmo en las décadas de 1930 y 1940.

\footnotetext{
${ }^{16}$ Borges (1989, III 358). En otro lugar, Borges observa lo siguiente: "Como los hechos referidos por la Escritura son verdaderos [...] debemos admitir que los hombres, al ejecutarlos, representaron ciegamente un drama secreto, determinado y premeditado por Dios" ("El espejo de los enigmas", Borges 1989, II 98).

17 Borges no distingue aquí entre el autor empírico (o redactor) del poema y su personaje-peregrino, como sí lo hace en "El último viaje de Ulises" y en "La última sonrisa de Beatriz" (Borges 1989, III 355 y 372 , respectivamente).
} 
Como he mostrado al inicio de este trabajo, Borges sostiene en "El escritor argentino y la tradición" que la libertad creadora es fuente de universalidad. A fin de sustentar su tesis, el autor recurre a un conocido ensayo del sociólogo norteamericano Thorstein Veblen, a saber, "The Intellectual Pre-eminence of Jews in Modern Europe", publicado en 1919. Siguiendo a Veblen, Borges indica que la contribución de la intelectualidad judía a la cultura europea tiene una explicación histórica antes que racial, y se debe al modo en que el pueblo judío-esparcido en occidente a causa de la diáspora-ha actuado dentro de ella sin sufrir un condicionamiento cultural que determine de manera especial su campo de acción. Añade, también, el caso de algunos pensadores irlandeses (Shaw, Berkeley, Swift), a quienes "les bastó el hecho de sentirse [...] distintos, para innovar en la cultura inglesa". Según Borges, algo similar le ocurre al escritor argentino con relación a la tradición occidental, razón por la cual también éste está en capacidad de "manejar todos los temas europeos, manejarlos sin supersticiones, con una irreverencia que puede tener, y ya tiene, consecuencias afortunadas" (1989, I 273).

Los ensayos, relatos y poemas con temas dantescos escritos por Borges a lo largo de su vida constituyen un buen ejemplo de aquella poética de la irreverencia promovida con tanto fervor en la conferencia de 1951. Lejos de afirmar un tratamiento paródico de la Comedia, dichas obras demuestran que el concepto de "irreverencia" - afín a su gusto por lo heterodoxo y lo herético—no implica la burla o el sarcasmo sino más bien una asimilación crítica, una postura intelectual que imprime el sello personal del autor frente a la tradición.

Open Access This article is distributed under the terms of the Creative Commons Attribution License which permits any use, distribution, and reproduction in any medium, provided the original author(s) and the source are credited.

\section{References}

Alonso, D. (2002). La escritura de la patria y el problema de la épica en el "Poema conjetural". En G. J. Racz (Ed.), Jorge Luis Borges at the Millenium (pp. 93-113). Lewiston: The Edwin Mellen Press. Arnold, M. (1962). Lectures and essays in criticism. In R. H. Super (Ed.). Ann Arbor, MI: The University of Michigan Press.

Balderston, D. (2013). Detalles circunstanciales: sobre dos borradores de "El escritor argentino y la tradición". Cuadernos Lirico,9, 2-12.

Bloom, H. (1997). The anxiety of influence: A theory of poetry. Oxford: Oxford U. P.

Borges, J. L. (1923). Fervor de Buenos Aires. Buenos Aires: Serrantes.

Borges, J. L. (1926). El tamaño de mi esperanza. Buenos Aires: Proa.

Borges, J. L. (1928). El idioma de los argentinos. Buenos Aires: Gleizer.

Borges, J. L. (1949). Estudio preliminar. En La Divina Comedia (pp. ix-xxviii). Buenos Aires: Editorial Jackson.

Borges, J. L. (1961). Mi primer encuentro con Dante. Quaderni italiani di Buenos Aires, 1, 91-94.

Borges, J. L. (1979). Borges oral. Buenos Aires: Emecé.

Borges, J. L. (1982). La fede poetica di Dante. Dante Studies, 1, 80-83.

Borges, J. L. (1989). Obras completas. 3 vols. Barcelona: Emecé.

Borges, J. L., \& Ferrari, O. (1987). Diálogos últimos. Buenos Aires: Editorial Sudamericana.

Carilla, E. (1963). Un poema de Borges (El "Poema conjetural”). Revista Hispánica Moderna,29, $32-45$.

Contreras, S. (2008). Intervenciones con Sarmiento: a propósito de "Historia de jinetes". In J. P. Dabove (Ed.), Jorge Luis Borges: políticas de la literatura (pp. 77-99). Pittsburgh: University of Pittsburgh. Cortínez, C. (Ed.). (1986). Borges, the poet. Fayetteville, AK: The University of Arkansas Press. 
Díaz, H. (2012). Borges, between history and eternity. London: Continuum International Publishing Group.

Durante, E. (2008). Poétique et écriture: Dante au miroir de Valéry et de Borges. Paris: Honoré Champion Éditeur.

Fiorucci, F. (2011). Intelectuales y peronismo, 1945-1955. Buenos Aires: Biblos.

Gil Guerrero, H. (2008). Poética narrativa de Jorge Luis Borges. Madrid: Iberoamericana; Frankfurt am Main: Vervuert.

Heaney, S., \& Kearney, R. (1983). Borges and the World of Fiction: An Interview with Jorge Luis Borges. The Crane Bag,7, 71-78.

Iglesias, M. C. (2012). Borges y sus tres interpretaciones del canto de Ulises en el Infierno de Dante. Modern Language Notes, 127, 282-301.

King, J. (1986). Sur: A study of the Argentine literary journal and its role in the development of a culture. Cambridge: Cambridge U. P.

Mazzotta, G. (1979). Dante, poet of the desert: History and allegory in the Divine Comedy. Princeton, NJ: Princeton U. P.

Núñez Faraco, H. (2012). Poesía y verdad en los escritos de juventud de Jorge Luis Borges. Bulletin of Hispanic Studies, 89, 645-654.

Paoli, R. (1977). Borges: percorsi di significato. Firenze: Università degli Studi di Firenze.

Paoli, R. (1984). Borges e Dante. Studi danteschi,56, 189-212.

Paoli, R. (1997). Borges e gli scrittori italiani. Napoli: Liguori Editore.

Rodríguez Risquete, F. (2005). Borges: fervor de Dante. Quaderns d'Italià,10, 195-218.

Sarlo, B. (1995). Borges, un escritor en las orillas. Buenos Aires: Compañía Editora Espasa-Calpe Argentina.

Siskind, M. (2007). El cosmopolitismo como problema político: Borges y el desafío de la modernidad. Variaciones Borges, 24, 75-92.

Sitman, R. (2003). Victoria Ocampo y Sur: entre Europa y América. Buenos Aires: Ediciones Lumiere. Waisman, S. (2005). Borges and translation: The irreverence of the periphery. Lewisbug: Bucknell U. P. 